\title{
Análise da produção científica brasileira sobre fluxos de informação
}

\author{
Danielly Oliveira Inomata \\ Universidade Federal de Santa Catarina - UFSC, Brasil \\ Wánderson Cássio Oliveira Araújo \\ Universidade Federal de Rondônia - UNIR, Brasil \\ Ketry Gorete Farias dos Passos \\ Universidade Estadual de Santa Catarina - UDESC, Brasil \\ Gregório Jean Varvakis Rados \\ Universidade Federal de Santa Catarina - UFSC, Brasil
}

\section{ANALYSIS}

\begin{abstract}
Resumo
Objetivo. Este artigo apresenta e discute os conceitos, contextos e aplicações que envolvem os fluxos de informação nas organizações. Método. Revisão sistemática, seguida de uma análise bibliométrica e análise sistêmica. $\mathrm{O}$ processo de revisão sistemática compreendeu as etapas de: 1) definição das palavras-chave, 2) revisão sistemática, 3) exploração e análise dos artigos e 4) comparação e consolidação dos resultados. Resultados. A análise bibliométrica apresentou um extrato dos artigos mais citados, período cronológico, periódicos e palavras-chave de maior ocorrência, visando fornecer um extrato da relevância dos artigos quanto aos autores, datas das publicações, índice de citação, periódicos e palavras-chave com maior ocorrência. Conclusões. Constatou-se que ao avançar dos anos, uma ênfase tem sido dada à questão das redes de informação e do conhecimento, ou seja, estudos estão se voltando para a operacionalização e análise dos fluxos de informação em redes. A literatura analisada demonstra a relação do fluxo de informação com a gestão da informação, aplicada a diferentes contextos organizacionais, inclusive mostrando novas tendências em Ciência da Informação como o estudo e analise do fluxo de informação em redes.
\end{abstract}

Palavras-chave

Fluxo da informação ; Rede de informação, Gestão da Informação ; Gestão do conhecimento ; Ciência da Informação ; Produção científica ; Brasil

\section{Analysis of the brazilian scientific production about information flows}

\begin{abstract}
Objective. This paper presents and discuss the concepts, contexts and applications involving information flows in organizations. Method. Systematic review, followed by a bibliometric analysis and system analysis. The systematic review aimed to search for, evaluate and review evidence about the research topic. The systematic review process comprised the following steps: 1) definition of keywords, 2) systematic review, 3) exploration and analysis of articles and 4) comparison and consolidation of results. Results. A bibliometric analysis aimed to provide a statement of the relevance of articles where the authors, dates of publications, citation index, and periodic keywords with higher occurrence. Conclusions. As survey results confirms the emphasis on information featured in the knowledge management process, and advancing years, it seems that the emphasis is on networks, ie, studies are turning to the operationalization and analysis of flows information networks. The literature produced demonstrates the relationship of information flow with its management, applied to different organizational contexts, including showing new trends in information science as the study and analysis of information flow in networks.
\end{abstract}

Information flow ; Information network ; Information management ; Knowledge management ; Information Science ; Scientific production ; Brazil 


\section{Introdução}

Estudos apontam a relevância da modelagem dos fluxos de informações como um fator crítico de agregação de valor, sendo a modelagem desse fluxo o processo descritivo de como as informações são transferidas ponto a ponto ao longo dos canais de comunicação na organização (BLACK; BRUNT, 1999; HIBBERD; EVATT, 2004; DURUGBO et al., 2013).

Conforme Durugbo et al. (2013), a modelagem do fluxo de informação para as organizações é motivada pela necessidade de entender melhor como: organizar e coordenar os processos, eliminar processos redundantes, minimizar a duplicação de informações e gerenciar o compartilhamento da informação intraorganizacional e interorganizacional.

No entanto, ressalta-se que o fluxo de informação é um processo que permite ter uma visão parcial da organização (OU-YANG; CHANG, 2000; COLLINS et al., 2010), uma vez que a visão global é parte dos outros processos: produção, recursos, custos, etc.

Para Valentim e Teixeira (2012) é necessário incentivar os fluxos de informação em todos os níveis organizacionais, no sentido de promover condições para a geração, compartilhamento e apropriação do conhecimento. Tem-se, portanto, a informação como insumo para a geração do conhecimento, de modo que a ação informacional será proporcional ao resultado da dinâmica do próprio fluxo, independente da qualificação da informação (como coisa, como conhecimento ou como processo), conforme Buckland (1991).

Sem dúvidas, tanto a cultura quanto a comunicação são aspectos que subsidiam a dinâmica da informação nas organizações (VALENTIM, 2010), ao mesmo tempo em que os fluxos de informação são considerados a forma motriz da organização (INOMATA, 2012) eles dependem do contexto organizacional para a ação. Com isso, "toda decisão e toda ação refletem, de alguma forma, o contexto e o clima organizacional, por meio de seus colaboradores" (VALENTIM; TEXEIRA, 2012, p. 154), apesar de a informação anteceder a decisão e ação (CHOO, 2006).

O objetivo da pesquisa é apresentar e discutir os conceitos, contextos e aplicações que envolvem os fluxos de informação nas organizações, por meio de uma revisão sistemática, seguida de uma análise bibliométrica e análise sistêmica.

\section{Metodologia}

Esta pesquisa se caracteriza como de natureza teórica-conceitual em relação ao tema abordado. Quanto aos seus procedimentos técnicos, enquadra-se como um estudo bibliográfico, pois tratará de dados e verificações provindas diretamente de trabalhos já realizados sobre o assunto pesquisado. Do ponto de vista dos objetivos, classifica-se como exploratória e descritiva, pois buscará informações específicas e características do que está sendo estudado (GIL, 2007).

Para a coleta de dados utilizou-se a revisão sistemática. Esse método busca identificar, avaliar e interpretar todas as pesquisas disponíveis, relevantes para uma particular questão de pesquisa, área, ou fenômeno de interesse (KITCHENHAM, 2007). Uma vez que pretende procurar sistematicamente e avaliar as evidências de pesquisa, tende a aderir a certas orientações sobre a conduta de uma revisão. Demonstrando, a qual permite a análise do que se sabe, recomendações para a prática, fatos desconhecidos, incerteza em torno de resultados e as recomendações para pesquisas futuras (GRANT; BOOTH, 2009).

Justifica-se o uso da revisão sistemática por serem replicáveis, transparentes e científicas. Além disso, possibilita a identificação de lacunas, bem como a identificação do conhecimento produzido, ou seja, o que se sabe, e consequentemente é possível identificar o que não se sabe.

Deste modo, realizaram-se procedimentos para a revisão sistemática, envolvendo três pesquisadores, especialistas em fluxos de informação. As etapas do processo foram as seguintes: 1) Definição das palavraschave, 2) Revisão sistemática, 3) Exploração e análise dos artigos, e 4) Comparação e consolidação dos resultados, conforme ilustrado na Figura 1: 


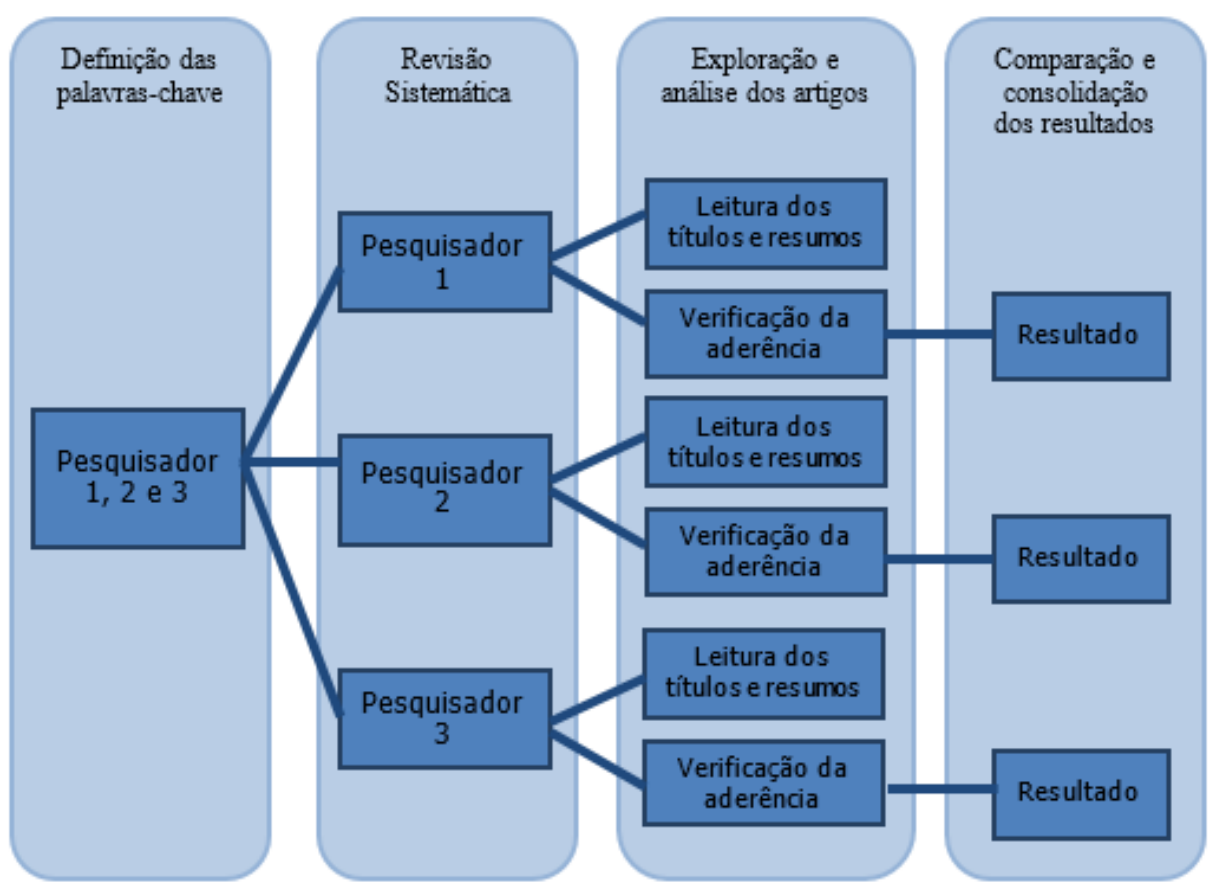

Figura 1 - Processos da Revisão Sistemática.

Para complementar a revisão sistemática, propôs-se a análise bibliométrica, para tratar os dados levantados com a busca na Base de Dados Referencial de Artigos de Periódicos em Ciência da Informação - BRAPCI. E com isso fornecer um extrato da relevância dos artigos, quanto aos autores, os anos das publicações, o índice de citação, os periódicos, as palavras-chave com maior ocorrência. A pesquisa considerou os artigos publicados em periódicos com Qualis A1, A2 e B1, considerados pela CAPES relevantes para produção intelectual dos Programas de pós-graduação (CAPES, 2014), conforme mostra o Quadro 1.

A escolha da BRAPCI se justifica pelo fato de ser uma base de dados brasileira da área da Ciência da Informação, a qual indexa a maioria dos periódicos da área. É importante ressaltar que os periódicos: In Texto, Tendências da Pesquisa Brasileira em Ciência da Informação e Revista Brasileira de Biblioteconomia e Documentação não são indexados pela Base de Dados BRAPCI, porém, por serem periódicos relevantes da área e por apresentarem QUALIS que se encaixam no escopo desta pesquisa, eles foram considerados.

\begin{tabular}{|c|c|l|c|}
\hline$\#$ & \multicolumn{1}{|c|}{ ISSN } & \multicolumn{1}{c|}{ TITULO* } & \multicolumn{1}{c|}{ QUALIS } \\
\hline 1 & $1518-8353$ & Ciência da Informação & B1 \\
\hline 2 & $1517-3801$ & Datagramazero (Rio de Janeiro) & B1 \\
\hline 3 & $1808-5245$ & $\begin{array}{l}\text { Em Questão: Revista da Faculdade de Biblioteconomia e Comunicação da } \\
\text { UFRGS }\end{array}$ & B1 \\
\hline 4 & $1518-2924$ & Encontros Bibli & B1 \\
\hline 5 & $1807-8583$ & In Texto (UFRGS. Online) & B1 \\
\hline 6 & $1981-8920$ & Informação \& Informação (UEL. Online) & B1 \\
\hline 7 & $1809-4783$ & Informação \& Sociedade (UFPB. Online) & A1 \\
\hline 8 & $1808-3536$ & Liinc em Revista & B1 \\
\hline 9 & $1981-5344$ & Perspectivas em Ciência da Informação (Online) & B1 \\
\hline 10 & $1678-765 X$ & Revista Digital de Biblioteconomia e Ciência da Informação & B1 \\
\hline 11 & $1983-5213$ & Revista Ibero-Americana de Ciência da Informação & A1 \\
\hline 12 & $1983-5116$ & Tendências da Pesquisa Brasileira em Ciência da Informação & \\
\hline 13 & $0103-3786$ & Transinformação & B1 \\
\hline 14 & $2236-417 X$ & Perspectivas em Gestão \& Conhecimento & B1 \\
\hline 16 & $0100-0691$ & Revista Brasileira de Biblioteconomia e Documentação \\
\hline 17 & $1809-4775$ & Biblionline & B1 \\
\hline
\end{tabular}

Quadro 1 - Periódicos da Ciência da informação 
Juntamente com a análise bibliométrica se fez a análise sistêmica. Na concepção de Ensslin et al. (2010), a análise sistêmica trata-se de um processo científico utilizado para, a partir de uma visão de mundo (filiação teórica) definida e explicitada por suas lentes. Segundo o autor, esse processo busca analisar uma amostra de artigos representativa, de um dado assunto de pesquisa visando evidenciar para cada lente e globalmente uma perspectiva, os destaques e as oportunidades (carências) de conhecimentos encontrados na amostra.

$\mathrm{Na}$ análise e discussão dos artigos levantados com a revisão sistemática serão detalhadas as informações pertinentes à pesquisa, bem como os critérios de seleção dos artigos.

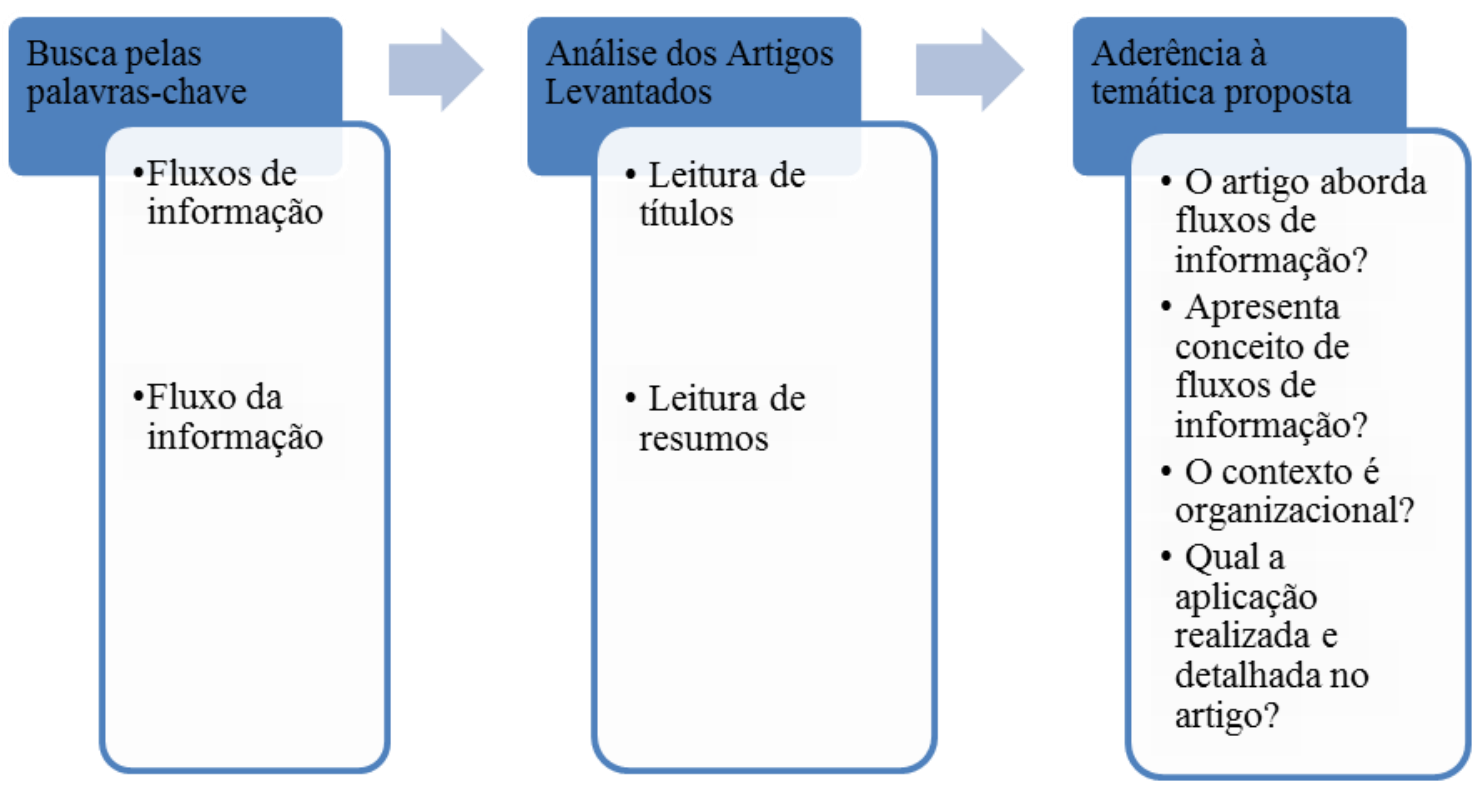

Figura 2 - Detalhamento dos critérios de seleção.

\section{A Ciência da Informação e os Fluxos de Informação}

A informação está presente, como insumo, em todas as atividades de uma organização, seja na tomada de decisão, no desenvolvimento de produtos dentre outros processos. A informação é a base do conhecimento, ela "tem por finalidade mudar o modo como o destinatário vê algo, exercer algum impacto sobre seu julgamento e comportamento. A informação não só 'dá forma ao receptor' como visa alguma finalidade" (DAVENPORT; PRUSAK, 2004, p. 5) à medida que esta informação percorre um caminho em forma de mensagem, na forma de um documento ou comunicação, intencionalmente. No entanto,

a relação entre informação e conhecimento só se realiza se a informação, instrumento modificador da consciência do homem e de seu grupo, for percebida e aceita pelo receptor, de forma a acrescentar um novo saber, sedimentar ou modificar o saber já estocado, colocando o indivíduo num estágio melhor de desenvolvimento. (BARRETO, 1996, p. 51).

Pode-se descrever um fluxo informacional como sendo um canal - tangível ou intangível, formal ou informal, permanente ou esporádico, constante ou intermitente -, constituído pela circulação de informações que fluem de uma determinada origem, geralmente um suporte/indivíduo, em sentido a um destino de armazenamento/processamento, podendo ocorrer a reversão desse fluxo até que os objetivos inicialmente estabelecidos sejam atingidos (GARCIA; FADEL, 2010).

Conforme destacado, o fluxo de informação é um processo dinâmico e complexo. Entender essa dinâmica requer resgatar conceitos iniciais, ou seja, a explosão da informação e a implosão do tempo. Para Le Coadic (2004), a conjunção destes dois fenômenos deu origem aos elevados fluxos de informação, além das fronteiras nacionais. Provocando a intensificação de atividades e métodos para o controle de dados e informações que envolvem problemas políticos, sociais, econômicos e culturais, mas que também permitem compreender o 
crescente e notório interesse pelo conhecimento e suas práticas, a gestão da informação, o monitoramento da informação, a inteligência competitiva, isto é, o mercado da informação e do conhecimento.

Os fluxos informacionais não são objetos de estudos exclusivos da Ciência da Informação, mas é nesta ciência que vem sendo realizado estudos relevantes, pelo fato do fluxo de informação ser um processo de mediação da informação gerada por uma fonte emissora e aceita por uma fonte receptora, podendo realizar uma das bases conceituais da Ciência da Informação (SAVI; SILVA, 2009). E principalmente, pela própria identidade da Ciência da Informação que objetiva investigar as propriedades e o comportamento da informação, as forças que governam o seu fluxo e os meios de processá-la para garantir acessibilidade e uso relevantes (SHERA; CLEVELAND, 1977).

Conforme observado por Sugahara e Vergueiro (2013), "a contribuição teórica para a Ciência da Informação em relação ao entendimento dos fluxos de informação nas redes sociais pode se dar a partir do estudo sobre o comportamento dos fluxos nessas redes", uma vez que os fluxos de informações movimentam as redes promovendo sua dinâmica (SUGAHARA; VERGUEIRO, 2013, p. 78), que com o uso da informação pelo receptor, após assimilação, expande o conhecimento que vai fortalecer o fluxo da informação e respaldar os processos individuais e coletivos (TOMAÉL et al., 2005).

A gestão da informação apoia o fluxo, que por sua vez: "[...] os fluxos informacionais são reflexos naturais dos ambientes ao qual pertencem, tanto em relação ao conteúdo quanto à forma" (VALENTIM, 2010, p. 13), portanto, dependem da dinâmica dos fluxos informacionais que dependem da própria estrutura organizacional e da comunicação em todos os níveis hierárquicos da organização (VALENTIM; TEXEIRA, 2012).

\section{Apresentação e Análise dos Resultados}

Nesta seção serão detalhados os resultados da pesquisa, considerando a junção dos dados dos três pesquisadores.

\subsection{Análise bibliométrica}

Ao todo foram recuperados 53 artigos a partir dos descritores de busca 'fluxo de informação' e sua variação no plural 'fluxos de informação'. Destes artigos, apenas 22 artigos estavam aderentes as lentes de verificação dessa pesquisa, ou seja, estavam relacionados ao contexto organizacional segundo a análise dos pesquisadores identificados como P1, P2 e P3 (Quadro 2). Como um primeiro resultado, já foi possível identificar o contexto das organizações em redes.

\begin{tabular}{|c|c|c|}
\hline PESQUISADOR & RECUPERADOS & \\
\hline P1 & 53 & 14 \\
\hline P2 & 52 & 13 \\
\hline P3 & 52 & 17 \\
\hline Retirada dos duplicados ou sem Qualis adequado & $\mathbf{2 2}$ \\
\hline
\end{tabular}

Quadro 2 - Resultado da busca de cada pesquisador. 
1. BRENNAND, Edna Gusmão de Góes; BRENNAND, Eládio José de Góes. Arquiteturas cognitivas e informacionais no contexto das dinâmicas sociais contemporâneas. Liinc em Revista, v. 6, n. 2, 2010.

2. CALAZANS, Angélica Toffano Seidel. Conceitos e uso da informação organizacional e informação estratégica. Transinformação, v. 18, n. 1, 2006.

3. CARVALHO, Kátia. Disseminação da Informação e Informação da Inteligência Organizacional. DataGramaZero: Revista de Ciência da Informação, v.2, n.3, p.1-9, jun, 2001.

4. DALBOSCO, Vagner; VIERA, Angel Freddy Godoy. Mediação tecnológica da informação no parlamento: estudo de uma assembleia legislativa no contexto brasileiro. Informação \& Sociedade: estudos, v. 21, n. 1, 2011.

5. KLINTOE, Kjeld. Interação entre empresas com necessidades de informação (= conhecimento) e a estrutura nacional de centros com provisão de conhecimento acumulado: referência especial à estrutura nacional de serviços de informação, documentação e de biblioteca. Ciência da Informação, v. 20, n. 1, p. 55-57, 1991

6. KREMER, Jeannette M. Fluxo de informação entre engenheiros: uma Revisão da Literatura. Revista da Escola de Biblioteconomia da UFMG, v. 9, n. 1, mar. 1980.

7. LEITÃO, Dorodame Moura. A informação: insumo e produto do desenvolvimento tecnológico. Ciência da Informação, Brasília, v. 14, n. 2, p.93-107, jul./dez., 1985.

8. LIMA JUNIOR, Oscar Pereira de; FREITAS, Adolfo Júlio Porto de. Estudo das disfunções do fluxo de informação do arquivo do departamento financeiro da empresa Z. S/A: aplicação da técnica 5W2H. Biblionline, v. 1, n. 1, jan./abr. 2005 .

9. LIMA, Rosa. Mais e melhores relacionamentos: uma proposta de metodologia de gestão da comunicação em arranjos produtivos locais. Liinc em Revista, v. 2, n. 2, 2006.

10. LOPES, Elaine Cristina; VALENTIM, Marta Lígia Pomim. Mediação da informação no âmbito do mercado de capitais. Informação \& Informação, Londrina, v. 13, n. esp., p. 87-106, 2008.

11. MORAES, Giseli de Almeida; Diniz; ESCRIVÃO FILHO, Edmundo A gestão da informação diante das especificidades das pequenas empresas. Ciência da Informação, v. 35, n. 3, p. 124-132, 2006.

12. PINTO, Virgínia Bentes. Informação: a chave para a qualidade total. Ciência da Informação, v. 22, n. 2, p. 133137, 1993.

13. RODRIGUES, Charles; BLATTMANN, Ursula. Uso das fontes de informação para a geração de conhecimento organizacional. Perspectivas em Gestão \& Conhecimento, v. 1, n. 2, 2011.

14. SAVI, Maria Gorete Monteguti; SILVA, Edna Lucia da. O fluxo da informação na prática clínica dos médicos residentes: análise na perspectiva da medicina baseada em evidências. Ciência da Informação, Brasília, v. 38, n. 3, set./dez. 2009.

15. STAREC, Claudio. Informação e Universidade: os pecados informacionais e barreiras na comunicação da informação para a tomada de decisão na universidade. DataGramaZero: Revista de Ciência da Informação, Rio de Janeiro, v. 3, n. 4, 2002.

16. SUGAHARA, Cibele Roberta; VERGUEIRO, Waldomiro de Castro Santos. Fluxo de informação na perspectiva do ambiente em rede. Revista Digital de Biblioteconomia e Ciência da Informação, Campinas, SP, v. 11, n. 2, p.76-97, maio/ago. 2013.

17. SUGAHARA, Cibele Roberta; VERGUEIRO, Waldomiro. Aspectos conceituais e metodológicos de redes sociais e sua influência no estudo de fluxos de informação. RDBCI, v. 7, n. 2, p. 102-117, 2010

18. TOMAÉL, María Inés. Redes sociais, conhecimento e inovação localizada. Informação \& Informação, Londrina, v. 12, n. esp., 2007.

19. TOMAÉL, María Inés; MARTELETO, Regina Maria. Redes sociais: posição dos atores no fluxo da informação. Enc. Bibli: Revista Eletr. de Bibliotecon. Ci. Inf., Florianópolis, n. esp., p. 75-91, 2006.

20. VAlENTIM, Marta Lígia Pomim; CARVALHO, Elizabeth Leão de; WOIDA, Luana Maia; CASSIANO, Elisete Lopes. Gestão da informação utilizando o método Infomapping. Perspectivas em Ciência da Informação, v. 13, n. 1 , jan./abr. 2008 .

21. VALENTIM, Marta Lígia Pomim; TEIXEIRA, Thiciane Mary Carvalho. Fluxos de informação e linguagem em ambientes organizacionais. Informação e Sociedade, João Pessoa, v. 22, n. 2, p.151-156, maio/ago. 2012.

22. VITAL, Luciane Paula; FLORIANI, Vivian Mengarda; VARVAKIS, Gregório. Gerenciamento do fluxo de informação como suporte ao processo de tomada de decisão. Informação \& Informação, Londrina, v. 15, n. 1, p. 85-103, jun./jul. 2010. 
Conforme apresentado no portfólio de artigos, somam 22 os artigos relevantes para a pesquisa, ou seja, que estão alinhados aos objetivos. A revisão sistemática dos artigos se mostrou adequada, como se pode observar no Quadro 3. Em seguida é apresentada a bibliometria dos artigos.

a) Principais autores: utilizou-se como critério para apresentação o ranking dos 15 autores com maior número de publicações.

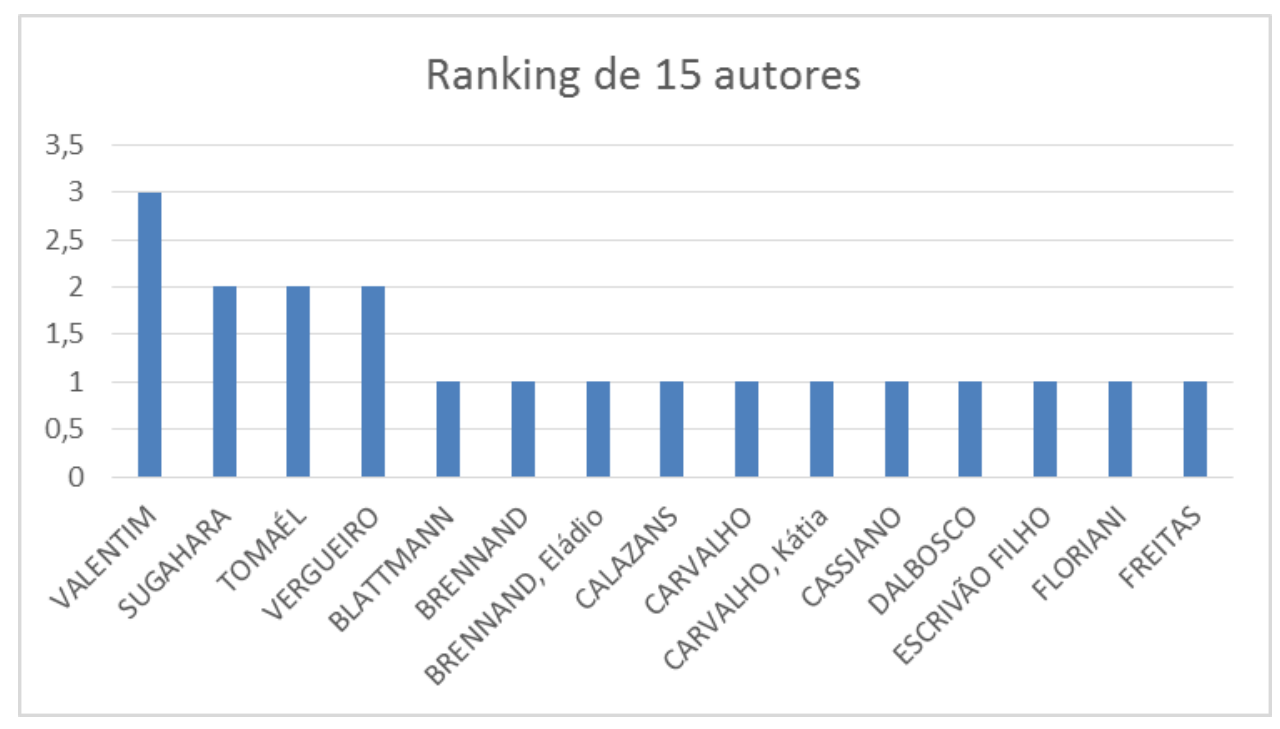

Gráfico 1 - Autores com maior número de publicações.

Valentim é a autora com o maior número de artigos, e de fato é reconhecida como uma das referências na área de Ciência da Informação. Na sequência aparece Sugahara, Tomaél e Vergueiro, com duas indicações de artigos cada um, esses autores tem publicado sobre fluxos de informação em redes.

Ao observar o Quadro 3, e comparar com os autores com o maior número de publicações sobre o tema fluxos de informação, pode-se verificar que todos esses autores trabalham em coautoria.

Embora tenha se detalhado os autores individualmente, dos 22 artigos relevantes para esta pesquisa, a maioria dos artigos possuem coautoria, somam 13 artigos, e nove são de autoria individual.

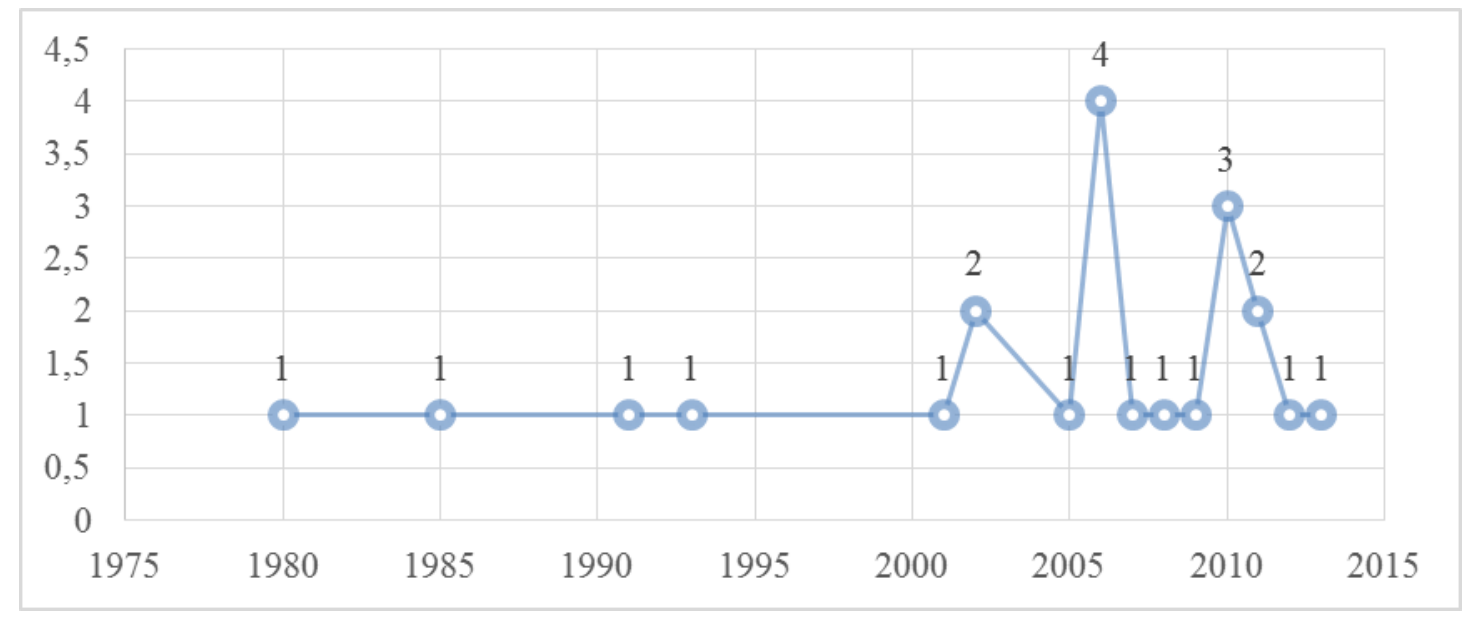

Gráfico 2 - Ano de publicação dos Artigos. 
Verifica-se que a partir dos anos 2000, as publicações sobre fluxos de informação foram mais evidentes, considerando a produção científica brasileira. Os anos de 2006 e 2007 foram aqueles com maior número de artigos publicados, as publicações abordavam fluxos de informação em redes, pequenas e medias empresas, APL e usos da informação.

b) Reconhecimento científico pelo número de citações: como são artigos nacionais, optou-se pela verificação de citações dos artigos no Google acadêmico.

Como destacam Pinto et al. (2010, p.204), "a citação é o meio mais comum de atribuir créditos e reconhecimento para aqueles cujos trabalhos têm contribuído para o desenvolvimento das ideias em diferentes campos". E o Google Acadêmico tem se mostrado uma excelente ferramenta também para a verificação de citação da produção científica (INOMATA; PINTRO, 2012).

\section{TÍTULO}

CITAÇÃO

\begin{tabular}{|c|c|}
\hline Fluxo de informação entre engenheiros: uma Revisão da Literatura & 78 \\
\hline Redes sociais: posição dos atores no fluxo da informação & 62 \\
\hline Informação: a chave para a qualidade total & 31 \\
\hline A gestão da informação diante das especificidades das pequenas empresas & 23 \\
\hline Disseminação da Informação e Informação da Inteligência Organizacional & 22 \\
\hline Gestão da informação utilizando o método Infomapping & 15 \\
\hline Conceitos e uso da informação organizacional e informação estratégica & 10 \\
\hline Redes sociais, conhecimento e inovação localizada & 9 \\
\hline Gerenciamento do fluxo de informação como suporte ao processo de tomada de decisão & 7 \\
\hline A informação: insumo e produto do desenvolvimento tecnológico & 6 \\
\hline Mediação da informação no âmbito do mercado de capitais & 5 \\
\hline Aspectos conceituais e metodológicos de redes sociais e sua influência no estudo de fluxos de informação & 5 \\
\hline $\begin{array}{l}\text { O fluxo da informação na prática clínica dos médicos residentes: análise na perspectiva da medicina baseada } \\
\text { em evidências }\end{array}$ & 3 \\
\hline $\begin{array}{l}\text { Informação e Universidade: os pecados informacionais e barreiras na comunicação da informação para a } \\
\text { tomada de decisão na universidade }\end{array}$ & 3 \\
\hline Uso das fontes de informação para a geração de conhecimento organizacional & 2 \\
\hline Mediação tecnológica da informação no parlamento: estudo de uma assembleia legislativa no contexto brasileiro & 2 \\
\hline $\begin{array}{l}\text { Mais e melhores relacionamentos: uma proposta de metodologia de gestão da comunicação em arranjos } \\
\text { produtivos locais }\end{array}$ & 2 \\
\hline Fluxos de informação e linguagem em ambientes organizacionais & 2 \\
\hline $\begin{array}{l}\text { Estudo das disfunções do fluxo de informação do arquivo do departamento financeiro da empresa Z. S/A: } \\
\text { aplicação da técnica } 5 \mathrm{~W} 2 \mathrm{H}\end{array}$ & 1 \\
\hline Arquiteturas cognitivas e informacionais no contexto das dinâmicas sociais contemporâneas & 0 \\
\hline $\begin{array}{l}\text { Interação entre empresas com necessidades de informação (= conhecimento) e a estrutura nacional de centros } \\
\text { com provisão de conhecimento acumulado: referência especial à estrutura nacional de serviços de informação, } \\
\text { documentação e de biblioteca. }\end{array}$ & 0 \\
\hline Fluxo de informação na perspectiva do ambiente em rede & 0 \\
\hline
\end{tabular}

\section{Quadro 4 - Reconhecimento científico.}

O artigo de Kremer (1980), o mais citado, "Fluxo de informação entre engenheiros: uma revisão da literatura" pode estar relacionado ao fato da autora apresentar uma vasta revisão de literatura acerca dos estudos de usuários e sua relação com o fluxo de informação. Para a autora, do ponto de vista do cientista ou tecnólogo são realizados estudos de comportamento, quando se estuda qualquer meio de comunicação são realizados estudos de uso e, por fim, do ponto de vista da ciência dos sistemas de comunicação tratam-se de estudos do fluxo de informação entre cientistas e tecnólogos.

O artigo de Tomaél e Marteleto (2006), "Redes sociais: posição dos atores no fluxo de informação" é o segundo artigo mais citado, uma justificativa pode ser o fato de utilizar a Análise de Redes Sociais, uma das metodologias 
de interesse para os estudiosos de fluxos de informação em redes. E por apresentar um caso prático, a exemplo da aplicação em uma rede social do consórcio de exportação de móveis, tendo como foco os indicadores de centralidade e de ligações fortes e fracas da rede.

O terceiro artigo com maior número de citações, de Pinto (1993), 'Informação: a chave para a qualidade total', que objetivou discutir a informação como crucial para a qualidade total, destacado pela autora como resultado principal: As Unidades de Informação devem investir em formas de oferecer informação precisa e de qualidade para seus usuários. A qualidade total foi um tema muito em voga na década de 90 , do século XX, o crescimento de publicações e interesse pelo tema na área a partir desse período podem ser os motivos para o índice de citações.

c) Principais periódicos: são detalhados os resultados dos artigos encontrados na busca e aderentes a pesquisa, por periódicos.

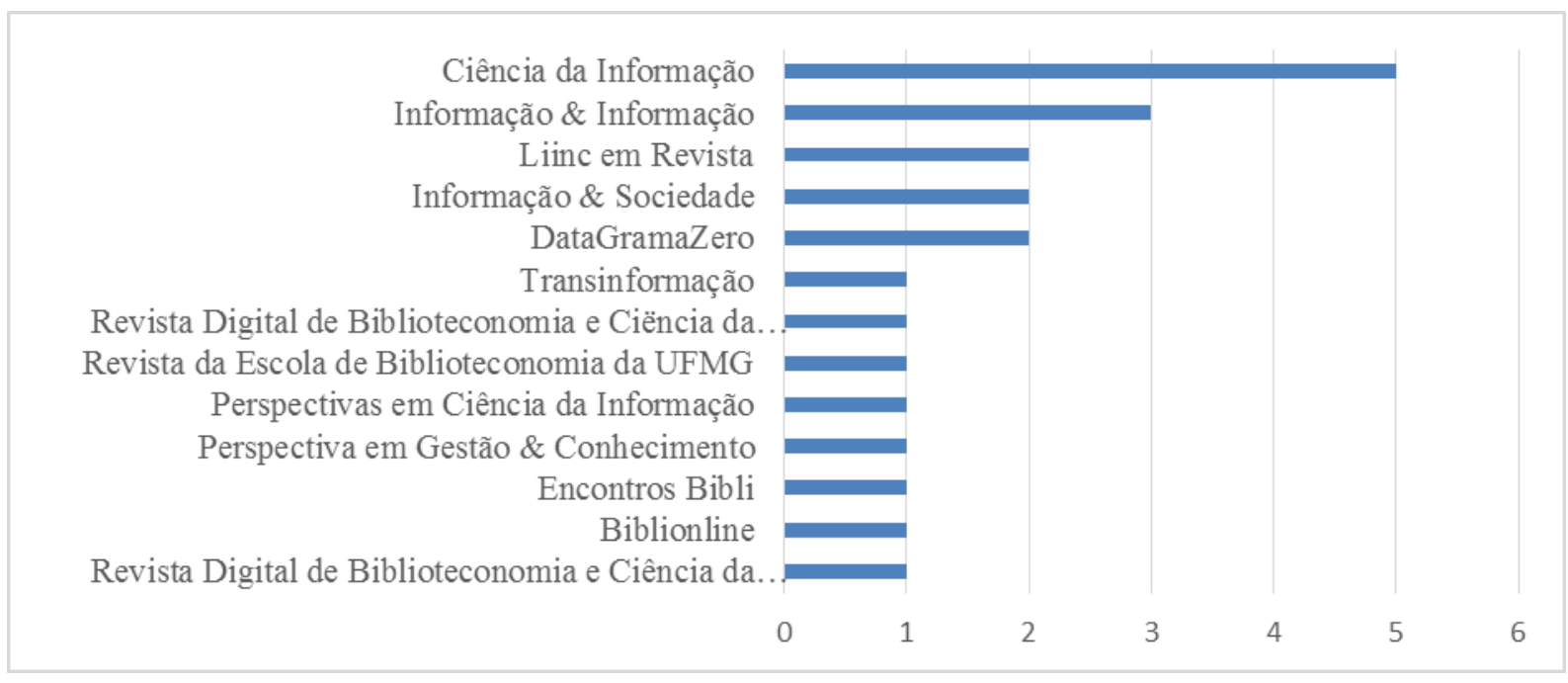

Gráfico 3 - Periódicos.

Como mostra os resultados dos periódicos com maior ocorrência de artigos publicados sobre fluxos de informação, os periódicos são: Ciência da Informação que possui Qualis A1, Informação e Informação, Liinc em Revista, Informação \& Sociedade e DataGramaZero, ambos com Qualis B1. O conjunto de periódicos com maior ocorrência se mostra adequado e coerente, visto que o escopo dos periódicos abrange a temática pesquisada.

d) Palavras-chaves: Além das palavras-chave utilizadas na busca, ao localizar as publicações nas bases de dados foram encontradas outras palavras-chave que se relacionam com o tema, como pode ser observado no Gráfico a seguir.

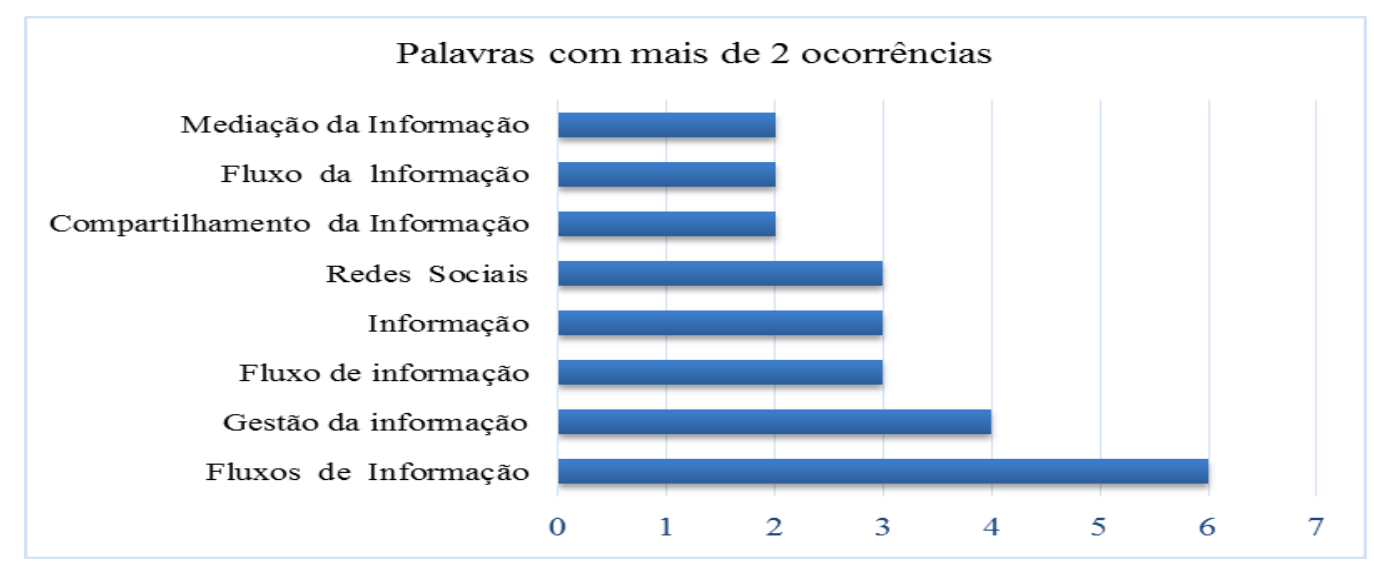

Gráfico 4 - Palavras-chave com maior ocorrência. 
A palavra-chave 'Fluxos de Informação' (6) utilizada para a pesquisa nas bases de dados é o descritor que possui maior ocorrência, isso valida a busca realizada. A palavra no singular 'Fluxo de Informação', aparece no Gráfico com três ocorrências. Um resultado coerente é a palavra 'Gestão da informação' com quatro ocorrências, e está altamente relacionada com fluxos de informação.

\subsection{Análise sistêmica}

O Quadro a seguir apresenta os conceitos encontrados sobre fluxos de informação, uma das lentes dessa análise, isto é, um dos objetivos do trabalho.

Em relação às considerações e implicações, os 22 artigos analisados apresentam resultados interessantes, que embora aplicados em organizações com diferentes culturas e políticas. Com a análise sistêmica dos artigos foi possível, também, identificar quais eram as definições utilizadas para fluxo de informação. O Quadro 5 apresenta tais definições.

\begin{tabular}{|c|c|}
\hline AUTOR (ANO) & DEFINIÇAO DE FLUXO DE INFORMAÇAO \\
\hline $\begin{array}{l}\text { Sugahara e Vergueiro } \\
\quad(2013, \text { p. } 78)\end{array}$ & $\begin{array}{l}\text { O fluxo de informação é um processo de comunicação com a intencionalidade do fenômeno da } \\
\text { informação, não objetiva somente uma passagem, e ao atingir ao público destinatário, o fluxo } \\
\text { modifica o estágio atual da condição humana. Esse desenvolvimento é repassado ao seu espaço } \\
\text { de convivência. Tal espaço pode expressar-se em uma estrutura social em rede. }\end{array}$ \\
\hline $\begin{array}{l}\text { Valentim e Teixeira } \\
\qquad(2012)\end{array}$ & $\begin{array}{l}\text { Fluxos de informação formais (estão diretamente relacionados a Gl. Objetivo: gerenciar a } \\
\text { imensa quantidade de informações, proveniente tanto do ambiente interno quanto externo, } \\
\text { proporcionando o acesso, o compartilhamento e a disseminação, por meio de documentos e } \\
\text { sistemas); } \\
\text { Fluxos de informação informais (estão diretamente relacionados a Gestão do Conhecimento. } \\
\text { Objetivo: aplicar ações direcionadas à criação/ construção, aquisição/apreensão, } \\
\text { compartilhamento/socialização e uso/aplicação de informação/conhecimento). Os fluxos } \\
\text { informais dependem exclusivamente das pessoas e da comunicação entre elas para ocorrer. } \\
\text { Estes fluxos devem ser integrados. Porém, a Gestão da Informação apoia-se nos fluxos formais } \\
\text { da organização, ou seja, no conhecimento explícito. }\end{array}$ \\
\hline Dalbosco e Vieira (2011) & $\begin{array}{l}\text { Baseado no conceito de Barreto (1998), afirmam que o fluxo consiste no processo de mediação } \\
\text { entre a geração de informação por uma fonte emissora e a aceitação da informação pela } \\
\text { entidade receptora, sendo esse processo composto por uma série de elementos e variáveis. }\end{array}$ \\
\hline $\begin{array}{c}\text { Rodrigues e Blattmann } \\
\text { (2011) }\end{array}$ & $\begin{array}{l}\text { Os fluxos de informação podem ser entendidos como as etapas que compreendem os momentos } \\
\text { de interação e transferência da mensagem entre um emissor e um receptor. }\end{array}$ \\
\hline $\begin{array}{l}\text { Vital, Floriani e Varvakis } \\
(2010)\end{array}$ & $\begin{array}{l}\text { Os fluxos de informação permitem o estabelecimento das etapas de obtenção, tratamento, } \\
\text { armazenamento, distribuição, disseminação e uso da informação no contexto organizacional. }\end{array}$ \\
\hline Savi e Silva (2009) & $\begin{array}{l}\text { O fluxo da informação é o processo envolvido na transferência da informação de um emissor } \\
\text { para um receptor. E na prática clínica, entende-se da seguinte forma: quando a informação } \\
\text { acessada pelo médico causar uma mudança na situação existente ou interferir na decisão clínica, } \\
\text { concentrando-se no que Barreto (2002 apud SAVI; SILVA, 2009) indica como fluxos extremos da } \\
\text { informação. }\end{array}$ \\
\hline Calazans (2006, p. 68) & $\begin{array}{l}\text { "O fluxo informacional é responsável pela qualidade da informação, sua distribuição e adequação } \\
\text { da informação às necessidades do usuário. A gestão da informação organizacional é realizada } \\
\text { através da coordenação, administração e planejamento do ambiente informacional e dos seus } \\
\text { fluxos de informação. [...] O modo como o fluxo informacional é implementado na organização } \\
\text { também influencia a informação estratégica". }\end{array}$ \\
\hline Leitão (1985, p. 99) & $\begin{array}{l}\text { O fluxo da informação em nível do indivíduo, simplificadamente, é um processo possui três } \\
\text { elementos principais: um emissor, uma mensagem (a informação) e um receptor. Em nível de } \\
\text { empresa considerando os seguintes componentes: P\&D, produção e comercialização, onde } \\
\text { "cada ator do processo pode exerce a função de emissor ou de receptor, dependendo da etapa } \\
\text { do processo. Esse fato permite constatar o caráter sistémico do fenômeno e sua característica de } \\
\text { processo sequencial. [...] O fluxo da informação também apresenta características similares ao } \\
\text { que se processa em nível do indivíduo. O início do processo se dá com a identificação de uma } \\
\text { necessidade da sociedade por parte da área de comercialização da empresa. } \\
\text { Em nível de país, "os principais atores nesse nível são, como receptor o país em } \\
\text { desenvolvimento que solícita, recebe a informação e aumenta seu aprendizado tecnológico e o } \\
\text { país desenvolvido que atua como emissor. Este é o fluxo de informação que se passa ao } \\
\text { início do processo de aprendizado ou desenvolvimento tecnológico. Outro fluxo de informação } \\
\text { identificado [...] é o que se passa dentro do país em desenvolvimento, onde o receptor é } \\
\text { a empresa com ou sem } P \text { \& D e que necessita atender a uma necessidade do país e como } \\
\text { emissor, os órgãos de } P \& D, \text { a universidade e/ou a literatura". }\end{array}$ \\
\hline Kremer (1980) & $\begin{array}{l}\text { É um termo utilizado para descrever a dinâmica do processo pelo qual a informação é } \\
\text { disseminada, procurada e obtida. }\end{array}$ \\
\hline
\end{tabular}

Quadro 5 - Definições de fluxos de informação, pelos autores do portfólio de artigos. 
Com a análise sistêmica dos artigos, observou-se que nem todos os autores apresentam claramente o conceito de fluxos de informação, isso demonstra que o termo está incorporado nos processos de gestão da informação. Em seguida são apresentados alguns apontamentos empregados nos artigos analisados, que demonstram em contextos diferenciados a análise ou processamento do fluxo de informação:

Na rede:

Sugaraha e Vergueiro (2010), baseados no trabalho de Marteleto (2001), compreendem que estudar o fluxo de informação nas redes sociais é preciso considerar as relações de poder, ou seja, relações que advêm de uma organização não-hierárquica e espontânea, com intenção de entender até que ponto a dinâmica do conhecimento e da informação interfere nesse processo.

Nas redes sociais, os atores integram-se aos fluxos de informação quando reconhecem a existência de opções de informação, de modo que:

tão importante quanto à oferta da informação é a capacidade de percepção da informação como informação pelos atores, pois esta percepção pode tanto impulsionar os fluxos existentes quanto propiciar o desenvolvimento de novos fluxos na rede. (SUGAHARA; VERGUEIRO, 2010, p. 107).

Como detalhado por Brennand e Brennand (2010, p.316), a rede além de complexa, por meio de "fluxos de informações tece nós, fractais e hologramas dos memoriais da humanidade, misturando culturas, imaginários e formas de ser, sentir e pensar numa plêiade de possibilidades de interação de saberes".

E conforme destaca Sugahara e Vergueiro (2013), as pessoas integram-se aos fluxos de informação quando reconhecem a existência de opções da informação que estão circulando na rede, considerando o contexto como um dos requisitos para a seleção da informação mais adequada.

Para Lima (2006), que estudou os fluxos de informação no contexto das APLs, os ativos intangíveis passam a ter peso fundamental na competitividade das organizações e precisam ser levados em conta em sua gestão. $E$ destaca que

ainda são muitas as lacunas no sentido de se definirem metodologias capazes de mapear os fluxos de informação e comunicação e identificar as trocas de conhecimento e de benefícios intangíveis presentes nesses APLs, de forma a possibilitar a formulação de estratégias que visem fortalecer os laços de interação entre os agentes que ali atuam. (LIMA, 2006, p. 135).

Para o autor, a pluralidade de agentes presentes em um APL contribui para que sejam geradas trocas intensas de valor entre eles e o ambiente onde atuam propiciando vários fluxos de conhecimento e aprendizado interativo. Porém, mesmo que se tenha uma proximidade espacial, maior interação e mais trocas de valor, por si só ela não é garantia de que isso ocorra. São necessárias outras condições, além da comunicação, como condições econômicas, sociais e institucionais, bem como a adoção de políticas e ações específicas que estimulem essa troca de valor (LIMA, 2006).

Também no contexto da APL, mas na Indústria Textil, Sugaraha e Vergueiro (2013) destacam que o número de ligações determina a dinâmica do fluxo de informação num ambiente em rede, no entanto os laços fracos da rede, ou seja, os nós com menor número de conexões, também são responsáveis pela dinâmica da rede, pois fomentam um fluxo de informação não-estruturado - informações não repetidas. Os autores acreditam que "as relações e posições dos atores são interdependentes. Assim, é importante observar o fluxo de informação a partir de cada elo em relação à rede como um todo" (SUGAHARA; VERGUEIRO, 2013, p. 89).

Sugahara e Vergueiro (2010) compreendem que uma vez que os fluxos de informação movimentam as redes, o direcionamento desses fluxos pode fortalecer e delinear uma rede, proporcionando sinergia às funções nela desdobradas. A informação mobiliza a rede e traz possibilidades de interação e expansão: "mediante o uso da informação, o estado existente modifica-se, expandindo o conhecimento que vai fortalecer o fluxo da informação e respaldar os processos individuais e coletivos" (TOMAÉL et al., 2005, p. 102).

Como o fluxo da informação em uma rede pode utilizar qualquer canal disponível e esse nem sempre é o mais curto, sugere-se empregar a centralidade de informação (TOMAÉL; MARTELETO, 2006).

Kremer (1980) aponta estudos de Paisley (1968) que afirma que o estudo do fluxo informacional deve considerar os seguintes aspectos: 1) todos os tipos de fontes de informação que estão disponíveis; 2) os futuros usos da informação; 3) a experiência, motivação, orientação, profissional e outras características individuais do usuário; 
4) os sistemas social, político, econômico e outros que afetam intensamente o usuário e seu trabalho e 5) as consequências do uso da informação. Nenhum estudo pode tratar de todos esses fatores ao mesmo tempo, mas alguns dos melhores chegam perto deste objetivo.

Kremer (1980) apresenta um conjunto de elementos apontados pela literatura que devem ser considerados quando do estudo do fluxo informacional, são eles: Estudos de necessidades de informação de cientistas e do público em geral de Faibisoff e Ely (1976) e apresentaram métodos para determinar essas necessidades. É importante distinguir entre as necessidades de informação declaradas dos usuários e as necessidades latentes. Menzel (1974) estudou as preferencias, experiências e o comportamento de cientistas e tecnólogos por canais de comunicação. Estudos sobre incidentes críticos, que procuram obter uma amostra de episódios de recebimento de informação, analisando como aconteceu, qual função da comunicação foi atendida, a satisfação do cientista com a informação obtida e outros assuntos. Allen mostrou as diferenças entre cientistas e engenheiros de pesquisa e desenvolvimento e estudou o desempenho e funções dos canais impressos e orais de informação (KREMER, 1980). Estudos usando técnicas sóciométricas de Crawford (1970) sobre "colégios invisíveis", apresentam um mapa mostrando a rede de comunicação e os nós de comunicação entre os atores das redes sociais. Holland (1972) citado por Kremer (1980) aponta ainda estudos sobre os gatekeepers e as características desses indivíduos que exercem influência sobre os outros dentro de redes de transmissão e recebimento de informação.

Na organização:

No contexto organizacional, todas as atividades geram dados, que podem se transformar em informações, cujos fluxos percorrem diversas áreas e geram novas informações, essas informações geralmente são sistematizadas em relatórios gerenciais que alimentam os sistemas informacionais, ou são canalizadas na tomada de decisão dos gerentes e diretores. Nesse contexto, a gestão da informação tem um poder transformador "[...] Como exemplo, pode-se destacar a elevação do grau de investimento em uma determinada empresa, a partir da divulgação de informações positivas sobre seus resultados financeiros" (LOPES; VALENTIM, 2008, p. 92).

O ponto de partida para a gestão da informação se inicia com a demanda de informação e o processo de atendimento a essa demanda, este último envolve o estudo da informação e suas características, fluxos e necessidades. Moraes e Escrivão Filho (2006) defendem que quanto menos estruturadas as organizações, menor será a eficiência da utilização das informações disseminadas. E à medida que aumenta a estruturação da empresa, percebe-se o aprimoramento na utilização das informações, sendo seu fluxo mais definido e formalizado. Apesar de estarem desestruturadas, principalmente nas organizações menores, as informações são distribuídas pelos níveis estratégico, tático e operacional por meio de fluxos informais de comunicação, que circulam pela empresa, sejam verbais, escritas ou eletrônicas, variando do mais verbal para o mais eletrônico da menor para a maior empresa, ou seja, quanto menor a empresa, mais verbal é a distribuição dessas informações e vice-versa. (MORAES; ESCRIVÃO FILHO, 2006).

Isso ocorre porque o processo de tomada de decisão varia de empresa para empresa, conforme o seu porte, ou seja, sua estrutura, formato de organização e, consequentemente, formalização dos processos.

Para Valentim et al. (2008), a gestão da informação pode utilizar diferentes métodos e técnicas que, aplicadas isoladamente ou em conjunto, obterão resultados efetivos quando à geração, uso e compartilhamento de dados, informação e conhecimento.

Rodrigues e Blattman (2011) consideram que estudos sobre gestão e fluxos de informação, fontes e usos da informação são necessários para compreender a gestão da informação como uma atividade organizacional. A obtenção de sucesso/êxito necessita ser realizada por pessoas apoiadas pelas tecnologias da informação e comunicação. Recomenda-se que o gerenciamento da informação seja realizado de forma processual, isto é, um conjunto de etapas conectadas horizontalmente e verticalmente de forma lógica e dialética, sendo abrangente/integrativo e específica, rígida (rigor na operação) e flexível (conforme a necessidade), e estar em constante aperfeiçoamento.

Como destacado por Vital et al. (2010, p. 86) em seu trabalho, "a literatura consultada é unânime em afirmar que a gestão da informação baseada no fluxo de informação é um recurso estratégico fundamental para o processo de tomada de decisão". E de fato o fluxo informacional exerce influência sobre a informação e vice-versa: "Um dos conceitos que influenciam diretamente a informação organizacional e, consequentemente, a informação estratégica é o fluxo informacional [...]" (CALAZANS, 2006, p.68). 
Calazans (2006) complementa que a informação no contexto organizacional é utilizada para agregar valor, tanto internamente como externamente, garantindo a sobrevivência e a competitividade das organizações. Porém, para que a informação seja eficaz é necessária sua correta gestão e administração. O principal objetivo da gestão da informação é identificar e potencializar os recursos informacionais de uma organização, ensinando-a a aprender e adaptando-se às mudanças ambientais. Portanto, na visão do autor o estudo do fluxo informacional tornará o processo de conhecimento das empresas mais eficaz.

Leitão (1985) analisou o relacionamento entre informação e o desenvolvimento tecnológico sob dois enfoques: (i) sobre o relacionamento do fluxo da informação com o desenvolvimento tecnológico, considerando-o como um processo de aprendizado, que ocorre em nível do indivíduo. E (ii) as diferenças existentes no relacionamento entre o fluxo da informação e o aprendizado tecnológico, para países desenvolvidos e em desenvolvimento.

A autora fundamenta que a informação é o insumo e o produto do desenvolvimento tecnológico. E que existe uma relação de causa e efeito muito grande entre a informação e o desenvolvimento tecnológico. Por esse motivo, é importante que se conheça bem como a informação circula a nível individual, porque é nesse nível que se definirá a eficácia de todo o processo, mesmo os maiores níveis de agregação, como o da empresa e o de país. No nível individual é fundamental que sejam estudadas as barreiras que interferem no fluxo da informação, como condição básica para que se possa agir no sentido de melhorar o processo.

\section{Conclusões}

Com esse levantamento bibliográfico, bem como com a análise sistêmica do conteúdo dos artigos, confirma-se a ênfase dada à informação que na década de 90 do século XXI iniciou o destaque ao processo de gestão do conhecimento (CALAZANS, 2006), e ao avançar dos anos, parece que a ênfase está nas redes, ou seja, estudos estão se voltando para a operacionalização e análise dos fluxos de informação em redes.

Pode-se constatar pela revisão de literatura que a gestão da informação é formada por um conjunto de ações que visa desde a identificação das necessidades informacionais, o mapeamento dos fluxos formais (conhecimento explícito) de informação nos diferentes ambientes da organização, até a coleta, filtragem, análise, organização, armazenagem e disseminação, objetivando apoiar o desenvolvimento das atividades cotidianas e a tomada de decisão no ambiente corporativo, como detalhado por Valetim et al. (2008).

Para que uma empresa seja bem-sucedida na tarefa de gerenciar a informação, precisa haver um consenso sobre o que é a informação dentro de uma organização, quem a possui, sob que forma é conservada, quem é o responsável pelo seu gerenciamento, e mais importante ainda, como controlar e utilizar a informação que existe em todas as organizações (MCGEE; PRUSAK, 1994).

As organizações contemporâneas caracterizam-se pela contínua produção, processamento e uso da informação, e os processos mais críticos estão na organização e o tratamento dessa informação. Evidencia-se a importância de um sistema que seja capaz de representar o conteúdo informacional dos documentos, de forma a possibilitar a sua futura recuperação (BARBOSA, 2008). Portanto, faz-se necessário analisar os modelos e os elementos que permeiam o fluxo informacional haja vista que a informação passa a ser concebida como matéria-prima para gerar o conhecimento. E o diferencial está na capacidade da organização gerar esse conhecimento, isto é, de dar senso útil às informações e conduzi-las no ambiente de negócios (COSTA, 2003).

Por fim, destaca-se alguns aspectos:

- A relevância do uso da metodologia de revisão sistemática neste trabalho, apoiada pela análise bibliométrica e sistêmica, realizada por especialistas se mostrou coerente ao atingir um resultado que permitiu monitorar e conhecer a produção cientifica nacional sobre fluxos de informação;

- A apresentação dos conceitos sobre fluxos de informação, sugerem a informação como um processo, uma sucessão de eventos, como já destacado por Barreto (1996; 2002), e também a informação como conhecimento;

- A literatura produzida demonstra a relação do fluxo de informação com a sua gestão, como visto aplicado a diferentes contextos organizacionais, inclusive mostrando 
novas tendências em Ciência da Informação, como o estudo e analise do fluxo de informação em redes.

- Está na agenda dos pesquisadores expandirem essa revisão sistemática em periódicos internacionais, para com isso monitorar o conhecimento produzido sobre fluxos de informação em cenário mundial.

\section{Referências}

BARBOSA, R. R. Gestão da informação e do conhecimento: origens, polêmicas e perspectivas. Informação \& Informação, Londrina, v. 13, n. esp., p. 1-25, 2008.

BARRETO, A. de A. A eficiência técnica e econômica e a viabilidade de produtos e serviços da informação. Ciência da Informação, Brasília, v. 25, n. 3, 1996.

BARRETO, A. de A. A condição da informação. São Paulo Perspectiva, v.16, n.3, 2002.

BLACK, A.; BRUNT, R. Information management in business, libraries and British military intelligence: Towards a history of information management. Journal of Documentation, v. 55, n. 4, pp. 361-374, 1999.

BRENNAND, E. G. de G.; BRENNAND, E. J. de G. Arquiteturas cognitivas e informacionais no contexto das dinâmicas sociais contemporâneas. Liinc em Revista, v. 6, n. 2, 2010.

BUCKLAND, M. 1991. Information as thing. Journal of the American Society for Information Science, v.42, n.5, p.351-360, 1991.

CALAZANS, A. T. S. Conceitos e uso da informação organizacional e informação estratégica. Transinformação, v. 18, n. 1 , 2006.

COLLINS, S. T.; BRADLEY, J. A.; YASSINE, A. A. Analyzing product development task networks to examine organizational change. IEEE Transactions on Engineering Management, v. 57, n. 3, pp. 513-525.

COSTA, M. R. D. Procedimentos para aplicação de mapas semânticos como estratégia para criação do conhecimento organizacional. Florianópolis, SC, 2003. 195 f. Tese (Doutorado em Engenharia de Produção) - Universidade Federal de Santa Catarina, 2003.

$\mathrm{CHOO}, \mathrm{C}$. W. Organização do conhecimento: como as organizações usam a informação para criar significado, construir conhecimento e tomar decisões. 2. ed. São Paulo: SENAC, 2006.

CRAWFORD, S. Y. Informal communication among scientists in sleep and dream research. PhD. Dissertation. Chicago, Illinois, University of Chicago, 1970.

DAVENPORT, T. H.; PRUSAK, L. Conhecimento empresarial: como as organizações gerenciam seu capital intelectual. 8a. ed. Rio de Janeiro: Campus, 2004.

DURUGBO, C. et al. Modelling information flow for organisations: A review of approaches and future challenges. International Journal of Information Management, v.33, p. 597-610, 2013.

GARCIA, R.; FADEL, B. Cultura organizacional e as interferências nos fluxos informacionais. In: VALENTIM, Marta (Org.). Gestão, mediação e uso da informação. São Paulo: Cultura Acadêmica, 2010.

INOMATA, D. O. O fluxo da informação tecnológica: uma análise no processo de desenvolvimento de produtos biotecnológicos. 2012. 282f. Dissertação (Mestrado em Ciência da Informação) - Programa de Pós-Graduação em Ciência da Informação, Universidade Federal de Santa Catarina, Florianópolis, 2012.

INOMATA, D. O.; PINTRO, P. Portais como ambientes de interação para inovação na sociedade do conhecimento, BIBLIOS Revista de Bibliotecología y Ciencias de la Información, n. 47, 2012.

ENSSLIN, L., ENSSLIN, S. R., LACERDA, R. T. O.; TASCA, J. E. ProKnow-C, Knowledge Development Process Constructivist. Processo técnico com patente de registro pendente junto ao INPI. Brasil, 2010.

FAIBISOFF, S.; ELY, D. P. Information and information needs. Information Reports and bibliographies, v. 5, n. 5, p. 2-16, 1976.

GIL, A. C. Como elaborar projetos de pesquisa. 4. ed. São Paulo: Atlas, 2007. 171p. 
GRANT, M. J. ; BOOTH, A. A typology of reviews: an analysis of 14 review types and associated methodologies. Health Information and Libraries Journal, v. 26, pp.91-108, 2009.

HIBBERD, B.; Evatt, A. Mapping information flows: A practical guide. The Information Management Journal, v. 38; n. 1, pp. 58-64, 2004.

HOLLAND, W. E. Characteristics of individuals with high information potential in government Research and Development organizations. IEEE Transactions on Engineering Management, n. 19, v. 44, May 1972.

KITCHENHAM, B. Guidelines for Performing Systematic Literature Reviews in Software Engineering. EBSE Technical Report, EBSE-2007-001, 2007.

KREMER, J. M. Fluxo de informação entre engenheiros: uma Revisão da Literatura. Revista da Escola de Biblioteconomia da UFMG, v. 9, n. 1, mar. 1980.

LE COADIC, Y. A Ciência da Informação. 2.ed. Brasília: Briquet de Lemos, 2004.

LIMA, R. Mais e melhores relacionamentos: uma proposta de metodologia de gestão da comunicação em arranjos produtivos locais. Liinc em Revista, v. 2, n. 2, 2006.

LOPES, E. C.; VALENTIM, M. L. P. Mediação da informação no âmbito do mercado de capitais. Informação \& Informação, Londrina, v. 13, n. esp., p. 87-106, 2008.

MARTELETO, R. M. Análise das redes sociais: aplicação nos estudos de transferência da informação. Ciência da Informação, Brasília, v. 30, n. 1, p.71-81, jan./abr. 2001

MCGEE, J.; PRUSAK, L. Gerenciamento estratégico da informação: aumente a competitividade e a eficiência de sua empresa utilizando a informação como uma ferramenta estratégica. Rio de Janeiro: Campus, 1994.

MENZEL, H. The information needs of current scientific research. The library Quarterly, v. 34, n. 1, pp. 4-19, Jan. 1974.

MORAES, G. de A. D.; ESCRIVÃO FILHO, E. A gestão da informação diante das especificidades das pequenas empresas. Ciência da Informação, v. 35, n. 3, p. 124-132, 2006.

OU-YANG, C.; CHANG, R. H. Applying an integrated analysis method to develop a shop floor control system. International Journal of Advanced Manufacturing Technology, v. 16, n. 5, pp.353-369, 2000.

PAISLEY, W. J. Information needs and uses. In: CUADRA, C. A. Annual Review of Information Science and Technology Chicago, Illinois, Encyclopaedia Britannica, v. 3, pp. 2, 1968.

PINTO et al. Visibilidade e monitoramento científico na área nuclear e ciências relacionadas: uma perspectiva a partir da produtividade do IPEN-CNEN/SP. Perspectivas em Ciência da Informação, v.15, n.2, p.198-218, maio./ago. 2010.

PINTO, V. B. Informação: a chave para a qualidade total. Ciência da Informação, v. 22, n. 2, p. 133-137, 1993

PROGRAMA de Pós Graduação em Ciência da Informação - PGCIN. Disponível em: <http://pgcin.paginas.ufsc.br/qualis/> Acesso em: 10.06.2014.

RODRIGUES, C.; BLATTMANN, U. Uso das fontes de informação para a geração de conhecimento organizacional Perspectivas em Gestão \& Conhecimento, v. 1, n. 2, 2011.

SAVI, M. G. M.; SILVA, E. L. da. O fluxo da informação na prática clínica dos médicos residentes: análise na perspectiva da medicina baseada em evidências. Ciência da Informação, Brasília, v. 38, n. 3, set./dez. 2009

SEHRA, J. H.; CLEVELAND, D. B. History and foundations of information Science. ARIST, v. $12,1977$.

SUGAHARA, C. R.; VERGUEIRO, W. Aspectos conceituais e metodológicos de redes sociais e sua influência no estudo de fluxos de informação. RDBCI, v. 7, n. 2, p. 102-117, 2010.

SUGAHARA, C. R.; VERGUEIRO, W. de C. S. Fluxo de informação na perspectiva do ambiente em rede. Revista Digital de Biblioteconomia e Ciência da Informação, Campinas, SP, v. 11, n. 2, p.76-97, maio/ago. 2013.

TOMAÉL, M. I. et al. Das redes sociais à inovação. Ciência da Informação, Brasília, v. 34, n. 2, maio/ago. 2005.

TOMAÉL, M. I.; MARTELETO, R. M. Redes sociais: posição dos atores no fluxo da informação. Enc. Bibli: Revista Eletrônica de Biblioteconomia Ciência da Informação, Florianópolis, n. esp., p. 75-91, 2006.

VALENTIM, M. L. P. et al. Gestão da informação utilizando o método Infomapping. Perspectivas em Ciência da Informação, v. 13 , n. 1, jan./abr. 2008.

VALENTIM, M. L. P. Ambientes e fluxos de informação. In: Ambientes e fluxos de informação. São Paulo: Cultura Acadêmica, 2010. 
VALENTIM, M. L. P.; TEIXEIRA, T. M. C. Fluxos de informação e linguagem em ambientes organizacionais. Informação e Sociedade, João Pessoa, v. 22, n. 2, p.151-156, maio/ago. 2012.

VITAL, L. Paula; FLORIANI, V. M.; VARVAKIS, G. Gerenciamento do fluxo de informação como suporte ao processo de tomada de decisão. Informação \& Informação, Londrina, v. 15, n. 1, p. 85-103, jun./jul. 2010.

\section{Dados dos autores}

\section{Danielly Oliveira Inomata}

Doutoranda em Ciência da Informação, Universidade Federal de Santa Catarina (UFSC/ PGCIN) - Turma 2013. Mestre em Ciência da Informação pela UFSC/ PGCIN - 2012, Especialista em Planejamento e Gerenciamento de Águas pela Universidade Federal do Amazonas - UFAM em 2007, Graduada em Biblioteconomia pela UFAM em 2005. Atua como pesquisadora no Grupo de Estudo e Pesquisa em Ciência da Informação (UFAM), no Grupo de Pesquisa: Informação, Tecnologia e Sociedade (UFSC) e no Núcleo de Gestão para Sustentabilidade NGS (UFSC). Competência de atuar nas áreas de Ciência da Informação, Biblioteconomia, Gestão do Conhecimento, Gestão da Informação e Comunicação, Fluxos Informacionais e áreas relacionadas.

inomata.danielly@gmail.com

\section{Wánderson Cássio Oliveira Araújo}

Professor efetivo do Departamento de Ciência da Informação da Universidade Federal de Rondônia. Mestre em Ciência da Informação, pela Universidade Federal de Santa Catarina, na área de concentração Gestão da Informação e linha de pesquisa em Fluxos de Informação. Bacharel em Biblioteconomia pela Universidade Federal do Ceará. Atua principalmente nos temas: gestão da informação, fluxo de informação, fontes de informação e inovação.

\section{wcassio@unir.br}

\section{Ketry Gorete Farias dos Passos}

Doutorando do Programa de Pós-Graduação pela Universidade Federal de Santa Catarina - UFSC (2015), Mestre em Ciência da Informação pela Universidade Federal de Santa Catarina - UFSC (2012). Possui Graduação em Biblioteconomia com habilitação em Gestão da Informação pela Universidade do Estado de Santa Catarina - UDESC (2009). Atualmente, é professora colaboradora do Departamento de Biblioteconomia e Gestão da Informação - DBI da Universidade do Estado de Santa Catarina - UDESC. Foi bolsista CAPESIPROF, atuando como tutora da disciplina de Ética do Profissional Arquivista, no Curso de Arquivologia da UFSC (2011). Foi pesquisadora do Núcleo de Pesquisa em Gestão da Sustentabilidade NGSIEGCIUFSC (2010-2012). Atuou na empresa Arquivo Contabilidade \& Consultoria (2012-2013) gerenciando o processo de GED do arquivo da empresa. Atuou como professora da Universidade Federal de Santa Catarina - UFSC (2009-2010), lecionou as disciplinas de Pesquisa Bibliográfica, Fontes de Informação II e Gestão de Documentos. Tem experiência em Gestão Eletrônica de Documentos, bem como na área de Pesquisa Bibliográfica. Tem experiência em pesquisa em Base de Dados internacionais desde 2008.

\section{ketry2003@gmail.com}

\section{Gregório Jean Varvakis Rados}

Possui graduação em Engenharia Mecânica pela Universidade Federal do Rio Grande do Sul (1979), mestrado em Engenharia de Produção pela Universidade Federal de Santa Catarina (1982) e doutorado em Manufacturing Engineering - Loughborough University of Technology (1991). Atualmente é professor associado da Universidade Federal de Santa Catarina, Depto de Engenharia do Conhecimento. Tem experiência na área de Gestão, com ênfase em Gestão de Processos Gestão do Conhecimento e Gestão de Organizações de Serviços, atuando principalmente nos seguintes temas: inovação, gestão do conhecimento, produtividade, melhoria contínua, tecnologia de informação e fluxo informacional. 


\section{AGRADECIMENTO:}

Os autores agradecem à Fundação de Amparo à Pesquisa do Estado do Amazonas - FAPEAM pela concessão de bolsa de estudo que possibilitou esta pesquisa (RH-POSGRAD MESTRADO 2009), finalizada em 2012.

$\begin{array}{ll}\text { Recebido - Received } & : 2015-02-09 \\ \text { Aceitado-Accepted } & : 2015-03-25\end{array}$

This work is licensed under a Creative Commons Attribution 4.0 United States License.

\section{UILIS D-Sorke}

This journal is published by the University Library System of the University of Pittsburgh as part of its D-Scribe Digital Publishing Program and is cosponsored by the University of Pittsburgh Press. 